\title{
Missing sputum samples are common in asthma intervention studies and successful collection at follow-up is related to improvement in clinical outcomes
}

\begin{abstract}
To the Editor:
Copyright @The authors 2022

This version is distributed under the terms of the Creative Commons Attribution NonCommercial Licence 4.0. For commercial reproduction rights and permissions contact permissions@ersnet.org

Received: 29 Oct 2021 Accepted: 21 Dec 2021

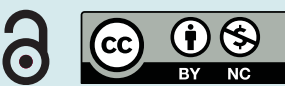

With only modest agreement between airway and systemic eosinophilia, biomarkers directly assessing the level and type of airway inflammation are becoming increasingly important, both for targeting treatment to the individual patient and for assessing effect [1].

A sputum cell differential count remains the gold standard for airway inflammometry in asthma but missing data are an inherent issue when utilising sputum-based outcome measures as the success rate for induction ranges markedly [2, 3]. It is well known that missing data potentially can lead to substantial bias when inadequately handled [4]. At present, reflections on how to handle missing sputum samples are largely absent in the literature and most studies defer to the use of baseline values to predict outcomes or utilise complete-case analysis despite evidence highlighting multiple imputation as the superior statistical method independent of the missingness of the data [2, 3, 5-8].

With the advances in the feasibility of sputum sampling in a clinical setting, we foresee a marked increase in the utilisation of sputum-based outcome measures, highlighting the necessity to evaluate the missingness of induced sputum $[9,10]$.

We hypothesised that any patient's ability to produce a sputum sample after receiving medical treatment is not random and that the proportion of missing samples is higher in patients with response to treatment, as a result of resolution of airway inflammation in general and the interleukin-13 driven mucus hypersecretion in particular [11]. Therefore, we pooled data on mannitol-induced sputum from three intervention studies $(n=135)$ with an aim to identify predictors of successful induction prior to and after a medical intervention.

The RECONSTRUCT study was a single-arm intervention study (1600 $\mu$ g inhaled budesonide once daily for 16 weeks) of steroid-free asthma patients with airway hyperreactivity (AHR) to mannitol (www. clinicaltrials.gov identifier number NCT03034005). The UPSTREAM study was a placebo-controlled intervention study (add-on of anti-thymic stromal lymphopoietin $(n=20)$ or placebo $(n=20)$ for 12 weeks) of predominantly moderate-to-severe asthma patients with AHR to mannitol [12]. The SIGNATURE study was a single-arm intervention study (add-on of $37.5 \mathrm{mg}$ oral prednisolone for 2 weeks) of patients with moderate-to-severe asthma [7].

Successful sputum induction was not required for inclusion in any of the studies and maintenance treatment prior to enrolment was continued unchanged throughout the study period. In all three studies, sputum was collected following a mannitol challenge test in a specimen jar (Petri dish) with the sample quality continuously evaluated by a trained laboratory technician. Samples were processed using the plug selection method, and cut-off values for eosinophilia and neutrophilia were $\geqslant 3 \%$ and $\geqslant 61 \%$, respectively [7, 12].

Shareable abstract (@ERSpublications)

Several factors significantly impact ability to produce a sputum sample after an anti-inflammatory intervention and these authors argue that the widely used complete-case analysis is inappropriate for paired sputum-based outcome measures https://bit.ly/3qN2pk5

Cite this article as: Frøssing L, Hvidtfeldt M, Silberbrandt A, et al. Missing sputum samples are common in asthma intervention studies and successful collection at follow-up is related to improvement in clinical outcomes. ERJ Open Res 2022; 8: 00612-2021 [DOI: 10.1183/23120541.006122021].
\end{abstract}


Three-quarters $(75 \%, \mathrm{n}=101)$ of patients were able to produce a sufficient sputum sample at baseline, two-thirds (65\%, $\mathrm{n}=88)$ at follow-up and paired samples were collected in half of the patients (52\%, $\mathrm{n}=70$ ). The success rate for collection of sputum at follow-up was equal in the placebo group and in the patients receiving active treatment, and we found no significant difference in the success rate between baseline and follow-up across all patients, in patients receiving active treatment, or in each study individually.

At baseline, neither demographics, lung function, AHR (provocative dose of mannitol causing a 15\% fall in forced expiratory volume in $1 \mathrm{~s}\left(\mathrm{FEV}_{1}\right)$ ) or inflammatory profile (blood eosinophils, exhaled nitric oxide fraction $\left(F_{\mathrm{ENO}}\right)$, immunoglobulin $\mathrm{E}$ and atopy) were significantly related to a successful collection.

In the patients receiving active treatment, success rate at follow-up was significantly higher in patients not receiving inhaled corticosteroids (ICS) at baseline (80\% versus 57\%; OR 4.3, p=0.006), and significantly lower in patients receiving treatment with a long-acting $\beta_{2}$-agonist ( $42 \%$ versus $72 \%$; OR $0.27, p=0.003$ ) and long-acting muscarinic antagonist (9\% versus 26\%; OR 0.29, $\mathrm{p}=0.02$ ) at baseline (figure 1). Similarly, patients with severe asthma according to European Respiratory Society/American Thoracic Society criteria had a significantly lower success rate compared to those without ( $54 \%$ versus $77 \%$; OR 0.31, $\mathrm{p}=0.008$ ) [13].

For patients receiving active treatment, those with the paucigranulocytic inflammatory phenotype at baseline had a significantly lower success rate at follow-up (41\% versus 59\%; OR 0.46, p=0.05). Successful collection at follow-up was not associated with other baseline inflammatory markers (sputum eosinophils, blood eosinophils and $F_{\mathrm{ENO}}$ ) or reduction in these.

Across all patients, successful collection of sputum at follow-up was significantly more prevalent in patients with improvement in $\mathrm{FEV}_{1}(200 \mathrm{~mL}$ and $12 \%)$ and $\mathrm{AHR}$ at follow-up measured with a mannitol challenge test (79\% versus 57\% (OR 2.4, $\mathrm{p}=0.02$ ) and 82\% versus 58\% (OR 3.3, $\mathrm{p}=0.01$ ), respectively). In the patients receiving active treatment, this remained significant for mannitol $(p=0.01)$ and showed a strong trend for $\mathrm{FEV}_{1}(\mathrm{p}=0.08)$.

We did not identify any factors affecting the success rate of induction at baseline; however, the likelihood of a successful induction post-intervention decreased with higher maintenance ICS doses at baseline and was, in line with our hypothesis, lower in the absence of airway inflammation (paucigranulocytic sputum). Surprisingly, a clinical response to treatment, with increase in lung function or improvement in AHR, was associated with a higher likelihood of a successful induction post-intervention. Speculatively, this could be explained by relief of airway obstruction that, in turn, allows for mobilisation of distal airway mucus plugs.

Interestingly, the level of maintenance treatment and the anti-inflammatory add-on intervention exerted opposite effects on the success rate. We believe this to be explained by the fact that they reflect different

Induction success rate

\begin{tabular}{|c|c|c|c|c|c|}
\hline & \multirow{2}{*}{$\begin{array}{c}\text { All } \\
(n=135)\end{array}$} & \multicolumn{2}{|c|}{ Upsteam } & \multirow{2}{*}{$\begin{array}{c}\text { Signature } \\
\text { OCS } \\
(n=48)\end{array}$} & \multirow{2}{*}{$\begin{array}{c}\text { Reconstruct } \\
\text { ICS } \\
(n=47)\end{array}$} \\
\hline & & $\begin{array}{c}\text { Anti-TSLP } \\
(n=20)\end{array}$ & $\begin{array}{c}\text { Placebo } \\
(n=20)\end{array}$ & & \\
\hline Baseline & $75 \%$ & $80 \%$ & $75 \%$ & $73 \%$ & $76 \%$ \\
\hline Follow-up & $65 \%$ & $55 \%$ & $60 \%$ & $58 \%$ & $80 \%$ \\
\hline $\begin{array}{l}\text { Paired } \\
\text { samples }\end{array}$ & $52 \%$ & $40 \%$ & $50 \%$ & $46 \%$ & $65 \%$ \\
\hline
\end{tabular}

Significant predictors of higher success rate at follow-up

- Absence of maintenance ICS treatment (OR 4.3)

- Decreased AHR at follow-up (OR 3.3)

- Improvement in $\mathrm{FEV}_{1}$ at follow-up $(2.4)^{+}$

Significant predictors of lower success rate at follow-up

- High-dose $e^{\S}$ maintenance ICS treatment (OR 0.31)

- Maintenance treatment with a long-acting bronchodilator (LABA: OR 0.27; LAMA: OR 0.29)

- Paucigranulocytic airway inflammation (OR 0.46)

FIGURE 1 Success rate of sputum induction in asthma and predictors of succesful induction at follow-up. TSLP: thymic stromal lymphopoietin; OCS: oral corticosteroid; ICS: inhaled corticosteroid; AHR: airway hyperreactivity; $\mathrm{FEV}_{1}$ : forced expiratory volume in $1 \mathrm{~s}$; LABA: long-acting $\beta_{2}$-agonist; LAMA: long-acting muscarinic antagonist. \#: proportion of patients with successful sputum at baseline and follow-up; ": normalisation of mannitol challenge test; ${ }^{+}: 200 \mathrm{~mL}$ and $12 \%$ improvement; ${ }^{\S}: 1600 \mu \mathrm{g}$ budesonide equivalent. 
aspects (traits) of disease: maintenance ICS dose is reflective of disease severity (i.e. chronicity) whereas response to add-on treatment reflects reversibility of disease, a notion we believe to be supported by the increase in success rate at follow-up in the steroid-naïve patients in the RECONSTRUCT study (figure 1).

Mannitol-induced sputum samples are of good quality, and are comparable with samples induced with hypertonic saline for the analysis of inflammatory cells and soluble markers [14, 15]. Further, the success rate for mannitol and hypertonic saline induction are similar, and the success rates reported in this study are equal to our own prior efforts using saline and to previous reports using mannitol $[3,14]$.

Still, we note several factors that potentially influence the generalisability of our findings to hypertonic saline-induced samples and we believe future studies confirming our results in hypertonic saline-induced samples are warranted. Wood et al. [14] reported a significantly lower total cell count (3.8 versus $2.1 \times 10^{6}$, $\mathrm{p}=0.003$ ) in samples induced with mannitol compared with hypertonic saline, which we believe may hamper our generalisability as we defined successful induction based on total cell count. Further to this point, Wood et al. [14] and Alvarez-Puebla et al. [15] have reported significant differences in inflammatory phenotype classification using mannitol and hypertonic saline induction respectively, which, as we found the paucigranulocytic phenotype to be significantly associated with a lower success rate at follow-up, again hampers the generalisability of our results.

Successful induction was defined based on identification of $\geqslant 250$ cells and we acknowledge that other cut-offs or criteria, such as viability, could have been chosen; however, as no consensus exists, this task is inevitably difficult and biased.

In summary, our findings suggest that the ability to produce repeated sputum is not random, and should be taken into account in the planning and analysis of interventions studies. Based on our findings, we believe that complete-case analysis is inappropriate for paired sputum-based outcome measures. We speculate that imputation better accommodates the missingness of sputum but future studies evaluating different methods for handling missing data are warranted [8].

Laurits Frøssing $\bullet$, Morten Hvidtfeldt, Alexander Silberbrandt, Asger Sverrild and Celeste Porsbjerg

Respiratory Research Unit, Dept of Respiratory Medicine, Copenhagen University Hospital, Bispebjerg and Frederiksberg, Denmark.

Corresponding author: Laurits Frøssing (froessing@dadlnet.dk)

Provenance: Submitted article, peer reviewed.

Conflict of interest: L. Frøssing has nothing to disclose. M. Hvidtfeldt has nothing to disclose. A. Silberbrandt has nothing to disclose. A. Sverrild has nothing to disclose. C. Porsbjerg has nothing to disclose.

References

1 Frøssing L, Silberbrandt A, Von Bülow A, et al. The prevalence of subtypes of type 2 inflammation in an unselected population of patients with severe asthma. J Allergy Clin Immunol Pract 2020; 9: 1267-1275.

2 Shaw DE, Sousa AR, Fowler SJ, et al. Clinical and inflammatory characteristics of the European U-BIOPRED adult severe asthma cohort. Eur Respir J 2015; 46: 1308-1321.

3 von Bülow A, Backer V, Bodtger U, et al. Differentiation of adult severe asthma from difficult-to-treat asthma - outcomes of a systematic assessment protocol. Respir Med 2018; 145: 41-47.

$4 \quad$ Little RJA, Rubin DB. Statistical Analysis with Missing Data. John Wiley \& Sons, Inc, 2002.

5 Berthon BS, Gibson PG, Wood LG, et al. A sputum gene expression signature predicts oral corticosteroid response in asthma. Eur Respir J 2017; 49: 1700180.

6 Peters MC, Kerr S, Dunican EM, et al. Refractory airway type 2 inflammation in a large subgroup of asthmatic patients treated with inhaled corticosteroids. J Allergy Clin Immunol 2019; 143: 104-113.

7 Frøssing L, Silberbrandt A, Von Bülow A, et al. Airway gene expression identifies subtypes of type 2 inflammation in severe asthma. Clin Exp Allergy 2022; 52: 59-69.

8 van der Heijden GJMG, Donders ART, Stijnen T, et al. Imputation of missing values is superior to complete case analysis and the missing-indicator method in multivariable diagnostic research: a clinical example. $J$ Clin Epidemiol 2006; 59: 1102-1109. 
9 Frøssing L, Hartvig Lindkaer Jensen T, Nielsen JØ, et al. Automated cell differential count in sputum is feasible and comparable to manual cell count in identifying eosinophilia. $J$ Asthma 2021; in press [https://doi. org/10.1080/02770903.2020.1868498].

10 Frøssing L, Kjærsgaard Klein D, Backer V, et al. The six-gene expression signature in whole sampled sputum provides clinically feasible inflammatory phenotyping of asthma. ERJ Open Res 2020; 6: 00280-2019.

11 Zhu Z, Homer RJ, Wang Z, et al. Pulmonary expression of interleukin-13 causes inflammation, mucus hypersecretion, subepithelial fibrosis, physiologic abnormalities, and eotaxin production. J Clin Investig 1999; 103: $779-788$.

12 Sverrild A, Hansen S, Hvidtfeldt M, et al. The effect of tezepelumab on airway hyperresponsiveness to mannitol in asthma (UPSTREAM). Eur Respir J 2022; 59: 2101296.

13 Chung KF, Wenzel SE, Brozek JL, et al. International ERS/ATS guidelines on definition, evaluation and treatment of severe asthma. Eur Respir J 2014; 43: 343-373.

14 Wood LG, Powell H, Gibson PG. Mannitol challenge for assessment of airway responsiveness, airway inflammation and inflammatory phenotype in asthma. Clin Exp Allergy 2010; 40: 232-241.

15 Alvarez-Puebla MJ, Olaguibel JM, Almudevar E, et al. Mannitol versus hypertonic saline: safety and efficacy of mannitol and hypertonic saline in sputum induction and bronchial hyperreactivity assessment. Chron Respir Dis 2015; 12: 197-203. 